\title{
Protocol
}

\section{In Vitro Histone Demethylase Assay}

\author{
Yu-ichi Tsukada ${ }^{1,2,3}$ and Keiichi I. Nakayama1 ${ }^{1,2,4}$ \\ ${ }^{1}$ Division of Cell Biology, Medical Institute of Bioregulation, Kyushu University, Fukuoka 812-8582, Japan \\ ${ }^{2}$ Core Research of Evolutional Science and Technology, Japan Science and Technology Agency, Kawaguchi, \\ Saitama 332-0012, Japan \\ ${ }^{3}$ Precursory Research for Embryonic Science and Technology, Japan Science and Technology Agency, \\ Kawaguchi, Saitama 332-0012, Japan
}

\section{INTRODUCTION}

Post-translational modifications of histones play an important role in regulating chromatin dynamics and function. One of the modifications, methylation, occurs on both lysine and arginine residues, and methylation status defines the epigenetic program of a cell by determining chromatin structure and thereby regulating DNA-dependent processes such as transcription. Until recently, histone methylation was considered to be irreversible. However, the discovery of histone demethylases revealed that histone methylation is more dynamic than previously recognized. This protocol describes two different in vitro histone demethylase enzyme reactions and three different methods for measuring histone demethylase activity. The first reaction (type I) uses the Fe(II)- and $\alpha$-ketoglutaratedependent dioxygenase family of histone demethylase (represented by JmjC domain-containing histone demethylase [JHDM]); the second (type II) is for the flavin adenine dinucleotide (FAD)-dependent amine oxidase family (represented by lysine-specific demethylase 1 [LSD1]). Histone demethylase activity can then be detected by measuring the release of radiolabeled formaldehyde from ${ }^{3} \mathrm{H}$-labeled methylated histone substrates, by monitoring the change in methylation levels of histone substrates by immunoblotting with site-specific methylhistone antibodies, or by using mass spectrometry to detect reductions in histone peptide masses that correspond to methyl groups. These assays can be applied to a wide range of histone demethylase studies, including the measurement of histone demethylase activity in tissue and cell lysates, identification of novel histone demethylases, and screening for inhibitors of histone demethylases.

\section{RELATED INFORMATION}

Based on proposed mechanisms for histone demethylation (Fig. 1), this protocol presents two different enzymatic reactions, type I and type II (data adapted from Tsukada and Zhang 2006).

\section{MATERIALS}

CAUTIONS AND RECIPES: Please see Appendices for appropriate handling of materials marked with $<!>$, and recipes for reagents marked with $<\mathbf{R}>$.

\section{Reagents}

$<$ ! $>$ 1-Pentanol (for scintillation counting only)

$<$ ! $>\alpha$-cyano-4-hydroxycinnamic acid $(10 \mathrm{mg} / \mathrm{mL})$ (for mass spectrometry only)

$<$ ! $>$ Acetonitrile (ACN) (for mass spectrometry only)

Antibodies, anti-methylated-histone, site-specific (for immunoblotting only)

${ }^{4}$ Corresponding author (nakayak1@bioreg.kyushu-u.ac.jp). 
$<$ R $>$ EDTA $(2 \mathrm{mM}$ ) (for mass spectrometry)

$<R>$ Histone demethylase dialysis buffer

$<R>$ Histone demethylase reaction buffer (type I)

$<\mathrm{R}>$ Histone demethylase reaction buffer (type II) can be used as an alternative, depending on the reaction type (see Step 3).

Histone methyltransferase (HMT), recombinant (for $\left[{ }^{3} \mathrm{H}\right]$-labeling only)

Histone octamers

Oligonucleosomes can be used as an alternative (see Step 1).

To prepare histone octamers or oligonucleosomes from HeLa cells, see Fang et al. (2004).

Histone peptides, methylated (for mass spectrometry only)

$<\mathbf{R}>$ Histone storage buffer (for octamers/oligonucleosomes)

$<\mathrm{R}>\mathrm{HMT}$ reaction buffer (for $\left[{ }^{3} \mathrm{H}\right]$-labeling only)

Liquid scintillation cocktail (for scintillation counting only)

Methyl-lysine analogs (MLAs) (for immunoblotting only)

To prepare MLAs, see Simon et al. (2007).

$<\mathrm{R}>\mathrm{NASH}$ reagent (for scintillation counting only)

Protein fractions

Recombinant enzymes can be used as an alternative (see Step 2).

Reagents for SDS-PAGE (for immunoblotting only)

$<\mathrm{R}>$ SDS loading buffer (5X) (for immunoblotting only)

$<$ !>Trichloroacetic acid (TCA) (for scintillation counting only)

$<$ ! Trifluoroacetic acid (TFA) (for mass spectrometry only)

\section{Equipment}

\section{Centrifuge}

Dialysis tubing

Empore extraction disk (3M) (for mass spectrometry only)

Incubators preset to $30^{\circ} \mathrm{C}, 37^{\circ} \mathrm{C}$

Mass spectrometer, matrix-assisted laser-desorption/ionization time-of-flight (MALDI-TOF; e.g., Autoflex; Bruker Daltonics) (for mass spectrometry only)

Micropipettor and tips

Nitrocellulose membrane (for immunoblotting only)

Scintillation counter (for scintillation counting only)

SDS-PAGE apparatus (for immunoblotting only)

Vortex mixer

Water bath preset to $95^{\circ} \mathrm{C}$ (for immunoblotting only)

\section{METHOD}

Separate procedures are presented to measure enzymatic activity by scintillation counting (Steps 4-11), immunoblotting (Steps 12-15), or mass spectrometry (Steps 16-22).

\section{In Vitro Histone Demethylation Reaction}

1. Prepare the substrate:

\section{To prepare $\left[{ }^{3} \mathrm{H}\right]$-labeled methylhistone octamers or oligonucleosomes}

i. Incubate 1.5-2.0 $\mu \mathrm{g}$ of histone octamers or oligonucleosomes purified from HeLa cells with different recombinant HMTs $(0.1-1.0 \mu \mathrm{g})$ in HMT reaction buffer for $1-2 \mathrm{~h}$ at $30^{\circ} \mathrm{C}$.

ii. Dialyze the reaction mixtures against histone storage buffer overnight in the presence (for type II reactions) or absence (for type I reactions) of $1 \mathrm{mM}$ EDTA to remove unincorporated radiolabel.

The labeled substrates are then ready for use in the demethylation reaction (see Step 3). 

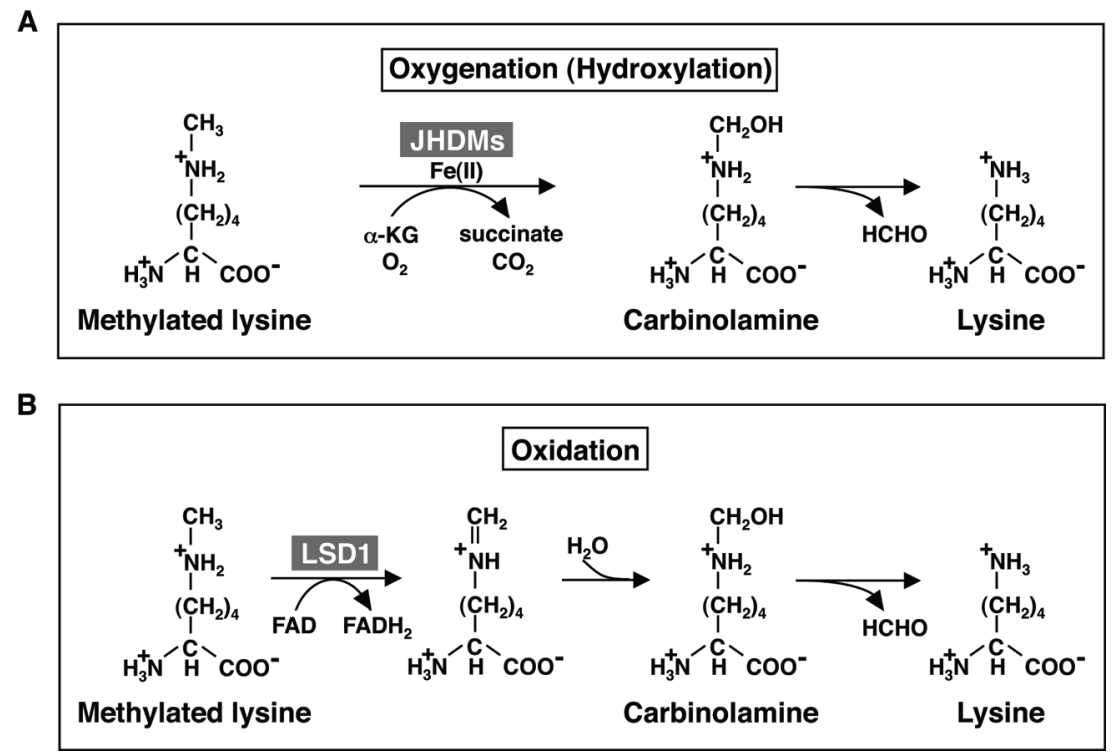

FIGURE 1. Two different mechanisms for histone demethylation. (A) Histone demethylation by oxygenation (hydroxylation) by JHDM family proteins, which use iron (Fe[II]) and $\alpha$-ketoglutarate $(\alpha-K G)$ as cofactors to catalyze addition of a hydroxyl group to a methyl group on methylated lysine. This generates unstable carbinolamine and succinate, and formaldehyde is released from carbinolamine. Only monomethyl lysine is shown here, but the same mechanism can be applied to demethylate di- or trimethylated lysine residues. (B) Histone demethylation by oxidation catalyzed by LSD1 family proteins. LSD1 catalyzes the transfer of two hydrogen atoms from methylated lysine to FAD to form an imine intermediate. The intermediate is hydrolyzed nonenzymatically to produce unstable carbinolamine, followed by release of formaldehyde. Although only monomethyl lysine is shown, the same mechanism can be applied to dimethylated lysine residues. This mechanism cannot be used to demethylate trimethylated lysine residues because the reaction requires a protonated nitrogen on the $\in$-amino group of lysine.

\section{To prepare octamers or oligonucleosomes for immunoblotting}

iii. Dialyze histone octamers or oligonucleosomes purified from HeLa cells against histone storage buffer in the presence (for type II reactions) or absence (for type I reactions) of 1 mM EDTA.

2. Dialyze the protein fractions or recombinant enzymes to be tested against histone demethylase dialysis buffer.

3. Incubate 1.5-2.0 $\mathrm{gg}$ of histone octamers or oligonucleosomes (with or without radiolabel, from Step 1.ii or Step 1.iii, respectively), or methylated histone peptides $(0.5 \mu \mathrm{g})$, or MLAs $(0.2-0.5 \mu \mathrm{g})$ with proper amount of protein fractions, or $03.3-3.0 \mathrm{mg}$ of recombinant enzymes (from Step 2) in type I or type II histone demethylase reaction buffer for $1-3 \mathrm{~h}$ at $37^{\circ} \mathrm{C}$.

Proceed to Step 4 (for scintillation counting), Step 12 (for immunoblotting), or Step 16 (for mass spectrometry), as appropriate.

\section{Detection of Released Radioactive Formaldehyde}

This procedure uses a modified NASH method (Kleeberg and Klinger 1982) to detect [ ${ }^{3} \mathrm{H}$-formaldehyde released by histone demethylation.

4. Stop the reaction (i.e., Step 3) by adding TCA to a final concentration of $12.5 \%$. Incubate the mixture for $15 \mathrm{~min}$ at $4^{\circ} \mathrm{C}$.

This precipitates the histone substrate and other proteins present in the reaction mixture.

5. Centrifuge the reaction at $16,000 \mathrm{~g}$ for $10 \mathrm{~min}$ at $4^{\circ} \mathrm{C}$. Remove the supernatant; measure its volume.

6. Add an equal volume of NASH reagent to the supernatant. 


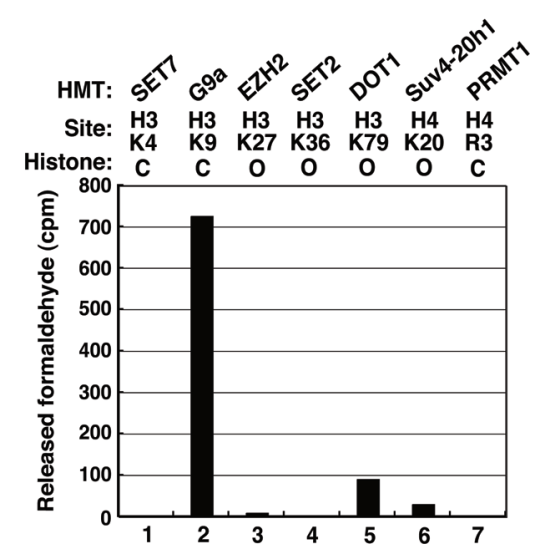

FIGURE 2. Histone demethylase activity of recombinant KDM7-FLAG with various methylated histone substrates, as measured by the release of radiolabeled formaldehyde. The HMTs used to generate the various substrates and their sites of methylation are indicated at the top. The methylated substrates were generated with the indicated forms of histone ( $\mathrm{C}$, core histone octamer; $\mathrm{O}$, oligonucleosome) based on the substrate preference of each HMT. The counts shown are corrected for control counts.

7. Incubate the mixture for $50 \mathrm{~min}$ at $37^{\circ} \mathrm{C}$ to convert the formaldehyde to 3,5 -diacetyl-1,4dihydrolutidine (DDL).

8. Add an equal volume of 1-pentanol to each sample. Vortex.

9. Centrifuge the reaction mixture at $16,000 \mathrm{~g}$ for $3 \mathrm{~min}$ at room temperature to separate the DDL into the 1-pentanol phase.

10. Recover the 1-pentanol phase. Mix with liquid scintillation cocktail.

11. Analyze by scintillation counting.

Figure 2 shows the resulting histone demethylase activity of recombinant KDM7 toward various methylated histone substrates as measured by this method.

\section{Detection of Methylated Histones by Immunoblotting}

12. Stop the reaction (i.e., Step 3) by adding a one-fifth volume of $5 X$ SDS loading buffer. Incubate for 5 min at $95^{\circ} \mathrm{C}$.

13. Separate the histones by SDS-PAGE on an $18 \%$ polyacrylamide gel.

14. Transfer the proteins to a nitrocellulose membrane.

15. Immunoblot with site-specific methylated histone antibodies following standard procedures. Figure 3 shows histone demethylase activity of recombinant KDM7 toward core histone substrates as measured by this method.

\section{Detection of Methyl Group Release by Mass Spectrometry}

16. Stop the reaction (i.e., Step 3) by adding $2 \mathrm{mM}$ EDTA.

17. Dilute an aliquot of the demethylation reaction mixture 10 -fold with $0.1 \%$ TFA and $2 \% \mathrm{ACN}$.

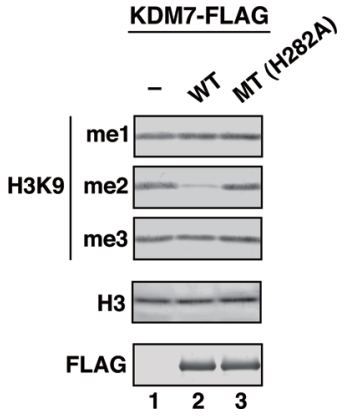

FIGURE 3. Immunoblot analysis of histone demethylase activity of wild-type (WT) or H282A mutant (MT) forms of recombinant KDM7-FLAG toward core histone substrates. The antibodies used are indicated to the left. 
18. Apply the sample to an Empore extraction disk packed into a pipette tip.

19. Wash the disk with $0.1 \% \mathrm{TFA} / 2 \% \mathrm{ACN}$.

20. Elute peptides with $5 \mu \mathrm{L}$ of $0.1 \% \mathrm{TFA} / 50 \% \mathrm{ACN}$.

21. Crystallize a fraction of the peptide pool with $10-\mathrm{mg} / \mathrm{mL} \alpha$-cyano-4-hydroxycinnamic acid.

22. Analyze the samples by MALDI-TOF. Figure 4 shows the histone demethylase activity of recombinant KDM7 toward H3K9me2 and H3K9me1 peptide substrates as measured by this method.

See Troubleshooting.

\section{TROUBLESHOOTING}

Problem: There is no activity with the use of peptides.

[Step 22]

Solution: Peptides that are too short can affect recognition of the substrate by histone demethylases. Try using a longer peptide.

\section{DISCUSSION}

Until recently, histone demethylases have been elusive in part because there was no sensitive assay to detect their activity. This protocol describes two reaction conditions and three methods for measuring activity. Each of the detection methods has advantages and limitations. Measuring the release of radioactive formaldehyde from ${ }^{3} \mathrm{H}$-labeled methylated histone substrates is the most sensitive technique, capable of detecting very low levels of activity in tissue and cell lysates. However, it is limited by the method of substrate preparation, which depends on the availability of HMTs to catalyze methylation of specific sites and statuses. Immunoblotting with site-specific methylhistone antibodies is easier to perform, but requires relatively high amounts of histone demethylase to detect activity. Because mass spectrometry uses synthesized peptides whose methylation sites and status are highly specific, this method can provide information regarding the substrate specificity of the enzyme. However, it requires the use of artificial peptides. Despite their various restrictions, the assays described here can be applied to study any demethylase that uses the same reaction mechanisms to demethylate any protein or nucleic acid.
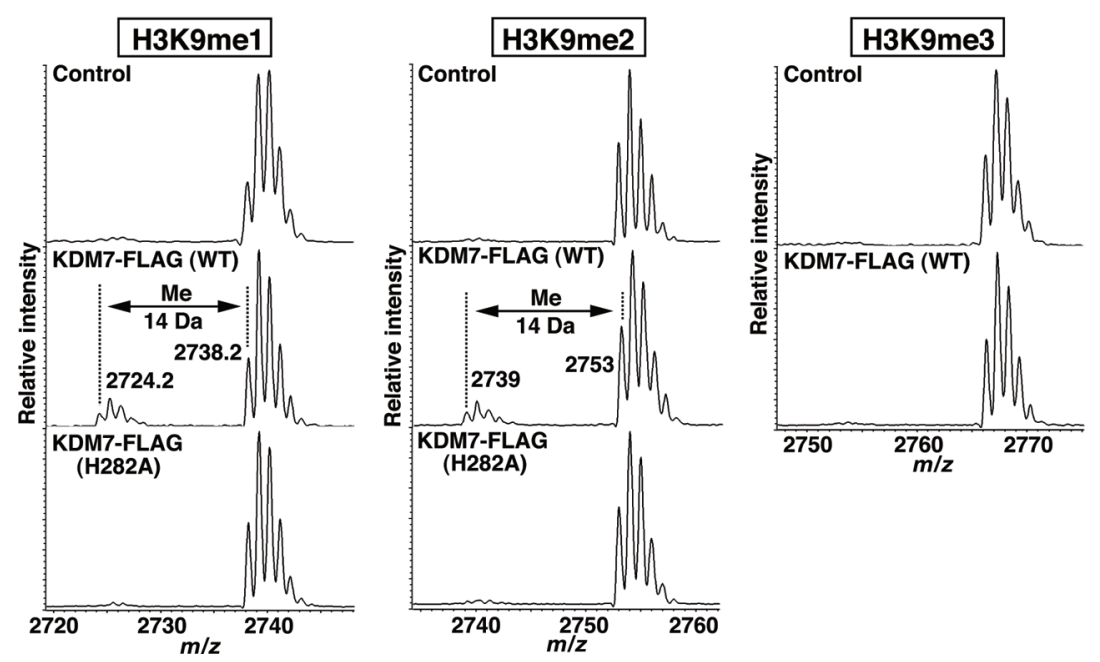

FIGURE 4. Mass-spectrometric analysis of the demethylase activity of wild-type (WT) or H282A mutant forms of KDM7-FLAG with methylated H3K9 peptide substrates. Numbers represent the mass-to-charge ratio of the substrate and product peptides. 


\section{REFERENCES}

Fang J, Wang H, Zhang Y. 2004. Purification of histone methyltransferases from HeLa cells. Methods Enzymol 377: 213-226.

Kleeberg U, Klinger W. 1982. Sensitive formaldehyde determination with Nash's reagent and a 'tryptophan reaction'. J Pharmacol Methods 8: 19-31.

Simon MD, Chu F, Racki LR, de la Cruz CC, Burlingame AL, Panning
B, Narlikar G], Shokat KM. 2007. The site-specific installation of methyl-lysine analogs into recombinant histones. Cell 128: $1003-$ 1012.

Tsukada Y, Zhang Y. 2006. Purification of histone demethylases from HeLa cells. Methods 40: 318-326. 


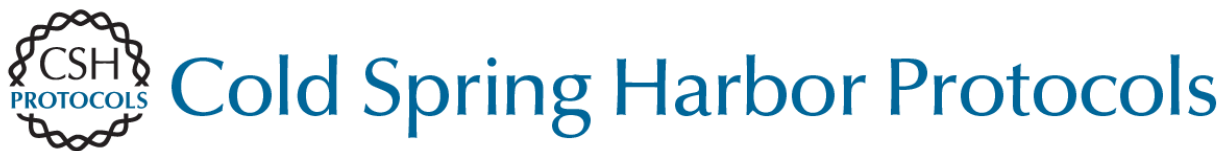

\section{In Vitro Histone Demethylase Assay}

Yu-ichi Tsukada and Keiichi I. Nakayama

Cold Spring Harb Protoc; doi: 10.1101/pdb.prot5512

\begin{tabular}{|c|c|}
\hline $\begin{array}{l}\text { Email Alerting } \\
\text { Service }\end{array}$ & Receive free email alerts when new articles cite this article - click here. \\
\hline $\begin{array}{l}\text { Subject } \\
\text { Categories }\end{array}$ & $\begin{array}{l}\text { Browse articles on similar topics from Cold Spring Harbor Protocols. } \\
\text { Antibodies, general ( } 289 \text { articles) } \\
\text { Characterization of Proteins ( } 208 \text { articles) } \\
\text { DNA Modification/Epigenetics ( } 42 \text { articles) } \\
\text { DNA:Protein Interactions ( } 74 \text { articles) } \\
\text { Immunoblotting (51 articles) } \\
\text { Mass Spectrometry (78 articles) } \\
\text { Molecular Biology, general (1293 articles) } \\
\text { Protein Identification and Analysis (202 articles) } \\
\text { Proteins and Proteomics, general (575 articles) }\end{array}$ \\
\hline
\end{tabular}

